\title{
ANALISIS SISTEM PENGENDALIAN INTERN PENERIMAAN KAS DARI PIUTANG PADA PERUSAHAAN JASA EKSPEDISI DI PT. TRANS MUTLI CARGO
}

\section{ANALYSIS OF CASH CONTROL INTERNAL CONTROL SYSTEM OF RECEIVA- BLES IN EXPEDITION SERVICE COMPANIES IN PT. TRANS MUTLI CARGO}

\author{
Dewanti Veronica Napitupulu ${ }^{1}$, Hendry Jaya ${ }^{2}$ \\ ${ }^{\text {I}}$ (Akuntansi, Ekonomi, Universitas Riau Kepulauan, Indonesia) \\ ${ }^{2}$ (Akuntansi, Ekonomi, Universitas Riau Kepulauan, Indonesia) \\ ljayahendry@yahoo.com
}

\begin{abstract}
Abstrak
Pengendalian intern yang baik sangat diperlukan atas penerimaan kas dari piutang untuk menghindari terjadinya kesalahan dalam proses akuntansi. Tujuan dari penelitian ini adalah untuk menganalisis efektifitas sistem pengendalian intern penerimaan kas dari piutang periode tahun 2017 di PT. Trans Multi Cargo. Teknik analisis data yang digunakan adalah deskriptif yaitu memberikan gambaran atas data yang diperoleh kemudian diolah, dianalisis dan membandingkan dengan teori yang relevan sesuai dengan dengan teori Mulyadi (2016) dan menguji efektifitas sistem pengendalian intern dengan metode Stop-Or-Go Sampling. Hasil penelitian menunjukkan bahwa sistem pengendalian intern penerimaan kas dari piutang di PT. Trans Multi Cargo sudah berjalan dengan baik. Hal ini tercermin dari sudah terpenuhinya unsur-unsur sistem pengendalian intern dan hasil dari pengujian kepatuhan untuk mengetahui efektivitas sistem pengendalian intern tidak ditemukan ada penyimpangan. Pada tingkat kesalahan sama dengan 0 , confidence level factor pada $R \%=95 \%$ adalah 3 , dengan demikian diperoleh $A U P L=5 \%$ sehingga $A U P L=D U P L$ sebesar $5 \%$ dan dapat ditarik kesimpulan bahwa sistem pengendalian intern penerimaan kas dari piutang sudah efektif.
\end{abstract}

Kata Kunci ; Pengendalian Intern, Penerimaan Kas dari Piutang

\begin{abstract}
Good internal control is a necessary for cash receipts from receivables to avoid the mistake in accounting process. The purpose of this research is to analyze the effectivity of internal control system of cash receipts from receivables period 2017 at PT. Trans Multi Cargo. Analysis technique data that is used in this research is descriptive method, that gives description of data obtained and then processed, analyzed and compared with relevant theory in accordance with Mulyadi's theory (2016) and test the effectivity of internal control system by Stop-Or-Go Sampling meth$o d$. The research result showed that the internal control system of cash receipts from receivables in PT. Trans Multi Cargo has been went really well. This is reflected in the fulfillment of internal control system elements and the result of compliance testing to determine the effectiveness of internal control system is not found any deviation. At the error level equal to 0 , the confidence level factor at $R \%=95 \%$ is 3 . Therefore, it was obtained AUPL $=5 \%$, and
\end{abstract}


$A U P L=D U P L$ of $5 \%$, so it can be concluded that the internal control system of cash receipts from receivables has been effective.

Keywords ; Internal Control, Cash Receipts From Receivables

\section{PENDAHULUAN \\ Latar Belakang Masalah}

Perusahaan ekspedisi adalah perusahaan penyedia jasa pengiriman baik transportasi melalui darat (truk / kontainer), udara (pesawat terbang), laut (kapal) antar wilayah maupun antar negara yang biasa dikenal dengan istilah ekspor - impor.

Dalam suatu perusahaan baik jasa maupun dagang mempunyaisebuah tujuan yaitu untuk memperoleh laba semaksimal mungkin. Untuk mencapai tujuan tersebut manajemen perusahaan harus mampu untuk mengelolah sumber daya yang ada pada perusahaan. Pengendalian intern yang dirancang dengan baik terhadap struktur organisasi perusahaan dalam pemisahaan tugas akan sangat membantu perusahaan dalam mencapai tujuan perusahaan

Sumber penerimaan kas suatu perusahaan pada umumnya berasal dari kegiatan operasional perusahaan seperti penjualan tunai dan kredit (baik perusahaan jasa maupun perusahaan dagang). Untuk penjualan kredit maka tidak segera menghasilkan penerimaan kas tetapi akan menimbulkan piutang. Mulyadi (2016) berpendapat bahwa sistem penagihan menjamin diterimanya kas dari debitur oleh perusahaan, dengan sistem pengendalian intern yang baik dapat menjaga aset organisasi, mengecek ketelitian dan keandalan data akuntansi.

PT. Trans Multi Cargo merupakan salah satu perusahaan ekspedisi dimana jangkauan pasarnya sudah cukup besar diberbagai daerah, selain dikota batam perusahan ini juga ada dibeberapa kota seperti Pekan Baru, Manado dan Jakarta. PT. Trans Multi Cargo adalah perusahaan penyedia jasa layanan untuk pengiriman barang berupa plastik scrub atau limbah B3 dan non - B3 (Bahan beracun dan berbahaya) baik antar wilayah maupun antar negara. Dalam kegiatannya sehari - hari PT. Trans Multi Cargo melakukan transaksi penerimaan kas dari pelunasan piutang, dimana sebagian besar piutang yang dilunasi tersebut adalah dari pelayanan jasa (jual jasa) yang disediakan oleh perusahaan tersebut. Penerimaan kas dari piutang seharusnya dapat berjalan dengan baik agar dapat menunjang berjalannya kegiatan operasional perusahaan, namun didalam pengelolaannya PT. Trans Multi Cargo masih mengalami permasalahan dalam penagihan piutang seperti keterlambatan customer dalam melakukan pembayaran piutang dan ada juga pembayaran piutang yang masih belum terselesaikan dan dapat menimbulkan piutang tak tertagih yang dapat menyebabkan perusahaan akan mengalami kerugian. Sesuai dengan teori Mulyadi (2016) piutang adalah hal yang sangat penting dalam tercapainya penerimaan kas oleh perusahaan.

Berdasarkan uraian diatas maka penulis tertarik untuk melakukan penelitian mengenai bagaimana sebenarnya sistem pengendalian intern penerimaan kas pada PT.Trans Multi Cargo sehingga penulis mengambil judul yaitu"Analisis sistem pengendalian intern penerimaan kas dari piutang pada perusahaan jasa ekspedisi di PT.Trans Multi Cargo".

\section{Batasan Masalah}

Penulis membatasi penelitian ini hanya pada sistem pengendalian intern penerimaan kas pelunasan piutang dari 
pemakaian jasa pada PT. Trans Multi Cargo periode tahun 2017.

\section{Rumusan Masalah}

Berdasarkan uraian dari latar belakang tersebut, maka perumusan masalah yang akan dibahas adalah "Bagaimana efektivitas sistem pengendalian intern penerimaan kas dari piutang pada PT. Trans Multi Cargo periode tahun 2017?"

\section{Tujuan Penelitian}

Untukmenganalisis efektivitassistem pengendalian intern penerimaan kas dari piutang di PT. Trans Multi cargo periode tahun 2017.

\section{TINJAUAN PUSTAKA}

\section{Definisi Sistem Pengendalian Intern}

Meliputi struktur organisasi metode dan ukuran - ukuran yang dikoordinasikan untuk menjaga aset organisasi, mengecek ketelitian dan keandalan data akuntansi, mendorong efisiensi dan mendorong dipatuhinya kebijakan manajemen. Defenisi sistem pengendalian intern tersebut menekankan tujuan yang hendak dicapai, dan bukan pada unsur-unsur yang membentuk system tersebut. Dengan demikian, pengertian pengendalian intern tersebut berlaku baik dalam perusahaan yang mengelolah informasinya secara manual, dengan mesin pembukuan, maupun dengan komputer (Mulyadi, 2016:129).

\section{Tujuan Sistem Pengendalian Intern}

Tujuan dari pengendalian intern menurut defenisi tersebut yang dikemukakan oleh Mulyadi (2016) adalah sebagai berikut :
1. Menjaga Asset perusahaan atau organisasi.

2. Mengecek ketelitian dan keandalan data akuntansi

3. Mendorong efisiensi

4. Mendorong dipatuhinya kebijakan manajemen

\section{Unsur Sistem Pengendalian Intern}

Menurut Mulyadi (2016), unsur pokok sistem pengendalian intern adalah sebagai berikut :

1. Struktur organisasi yang memisahkan tanggung jawab fungsional secara tegas.

2. Sistem wewenang dan prosedur pencatatan yang memberikan perlindungan yang cukup terhadap aset, utang, pendapatan dan beban.

3. Praktik yang sehat dalam melaksanakan tugas dan fungsi setiap organisasi.

4. Karyawan yang mutunya sesuai dengan tanggung jawabnya.

Kas

Kas meliputi uang logam, uang kertas, cek, wesel pos (kiriman uang lewat pos; money orders) dan deposito. Pada umunya, perusahaan membagi kas menjadi dua kelompok, yaitu uang yang tersedia dikasir (cash on hand) dan uang yang tersimpan di bank (cash in bank). Dalam neraca kas selalu disajikan dalam urutan pertama, setelah itu barulah diikuti dengan akun piutang usaha dan seterusnya sesuai dengan tingkat likuiditasnya. Dengan kas yang dimiliki, perusahaan dapat membeli barang dagangan dari supplier lalu menjual kembali kepada pelanggan, yang sebagian besar dilakukan secara kredit dan timbullah piutang usaha. Piutang usaha inilah yang akan ditagih yang kemudian akan menghasilkan kas dan se- 
terusnya dimana siklus ini akan berulang kembali (Hery, 2013;153-154).

\section{Sumber Penerimaan Kas}

Sumber penerimaan kas suatu perusahaan salah satunya berasal dari pelunasan piutang dari debitur. Berdasarkan sistem pengendalian intern yang baik, sistem penerimaan kas dari piutang harus menjamin diterimanya kas dari debitur oleh perusahaan bukan oleh karyawan yang tidak berhak menerimanya. Penerimaan kas dari piutang dapat dilakukan melalui penagih perusahaan, melalui pos, dan melalui lock-box collection plan (Mulyadi, 2016;403).

\section{Pengujian Kepatuhan Terhadap Pengen- dalian Intern}

Pengujian kepatuhan digunakan untuk menguji efektifitas sistem pengendalian intern dalam suatu organisasi dalam mencapai tujuannya.

\section{Attribut Sampling Untuk Menguji Efek- tifitas Sistem Pengendalian Intern Pen- erimaan Kas Dari Piutang}

Menurut Mulyadi dalam Rahayu Wijayanti (2009) ada 3 model attribute sampling yaitu :

1. Fixe-Sample-Size-Attribute Sampling Pengampilan sampel dengan model ini memperkirakan persentase terjadinya mutu tertentu dalam suatu populasi, model ini digunakan untuk melakukan pengujian terhadap unsur sistem pengawasan intern dan untuk memperkirakan akan menjumpai beberapa penyimpangan. Kriteria yang digunakan dalam model ini adalah Desired Upper Precision Limit (DUPL) dan Achieved PrecisionLimit(AUPL).Apabila AUPL $\leq$ DUPL maka secara statistik dapat disimpulkan bahwa system pengendalian intern sudah efektif.

2. Stop-Or-Go Sampling

Model ini dapat mencegah dari pengambilan sampel yang terlalu banyak.Adapunprosedur penggunaannya Stop-Or-Go Sampling adalah :

1. Menentukan batas ketepatan atas yang diinginkan (Desired Upper Precision Limit atau UPL) dan (Confidence Level atau tingkat keandalan) Pada tahap ini auditor menentukan tingkat keandalan yang akan dipilih dan tingkat kesalahan maksimum yaitu memilih tingkat kepercayaan $90 \%, 95 \%$, atau $97,5 \%$

2. Setelah tingkat keandalan dan DUPL ditentukan selanjutnya menentukan besarnya sampel minimum yang harus diambil oleh penulis dengan bantuan tabel besarnya sampel minimum untuk pengujian pengendalian, jika hasil pengujian baik penulis disarankan untuk menggunakan tingkat keandalan kurang dari $95 \%$ dan menggunakan Desired Upper Precision Limit lebih dari 5\% dan sampel kurang dari 60 sampel.

3. Pembuatan tabel Stop-Or-Go Sampling dan analisis hasil pemeriksaan sampel, dalam tabel tersebut sampel diambil sebanyak 4 kali. Dan rumus untuk menghitung AUPL yaitu

$$
\begin{aligned}
& \text { Confidence level } \\
& \text { factor at desired } \\
& \text { reliability level } \\
& \text { for occurrances }
\end{aligned}
$$

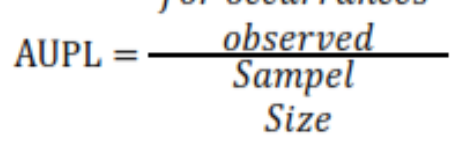

saan sampel diperlukan hasil pemerikuntuk menen- 
tukan confidence level. Apabila pemeriksaan sampel dan akhir ditemukan kesalahan maka perlu menambahkan sampel lagi dengan perhitungan,

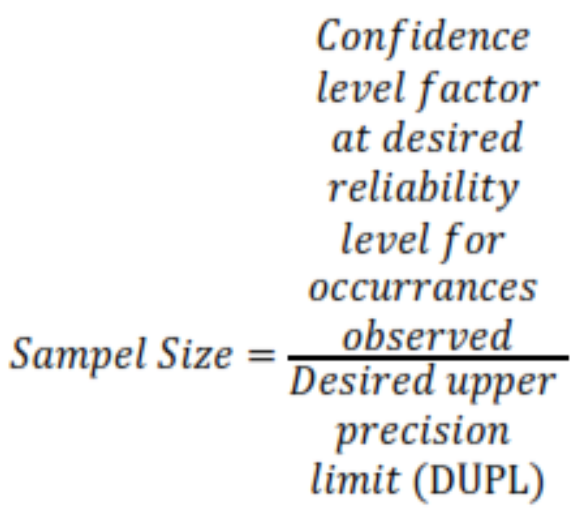

Kriteria efektivitas system pengendalian intern menurut model ini jika tingkat kesalahan sama dengan nol.

Keterangan :

AUPL = batas ketepatan atas yang diterima DUPL $=$ batas ketepatan atas yang diinginkan

3. Discovery Sampling

Model ini cocok digunakan jika tingkat kesalahan yang diperkirakan dalam populasi mendekatinol.Discovery sampling digunakan untuk menemukan kecurangan dari sistem pengawasan intern.

\section{Penelitian Terdahulu}

Ainun Nadlifah (2014), Evaluasi Pengendalian Internal Penerimaan Kas Dari Piutang (Studi pada Perusahaan Timbangan PT Panggung Baru Semarang), hasil penelitian menunjukkan Pengendalian internal penerimaan kas dari piutang PT Panggung Baru Semarang belum memenuhi unsur-unsur pengendalian internal yang memadai. Eni Pirnawati (2013), Sistem Akuntansi Penerimaan Kas Dari Piutang Pada Koperasi Serba Usaha (Ksu) Makmur
Abadi Kecamatan Kayen Kabupaten Pati, hasil penelitian sistem akuntansi penerimaan kas dari piutang pada KSU Makmur Abadi sudah cukup baik namun terdapat kelemahan pada penagihan yang seharusnya dilakukan oleh fungsi penagihan akan tetapi bias dilakukan oleh kasir. Fungsi piutang dan fungsi akuntansi dilakukan oleh satu orang yang sama.

\section{METODOLOGI PENELITIAN Objek Dan Lokasi Penelitian}

Objek dalam penelitian ini dilakukan di PT.Trans Multi Cargo yang berlokasi di Repindo Industrial Estate Blok A2 N0.4 Batu Ampar, Kota Batam, Kepulauan Riau, Kode Pos : 29444, Telepon / Fax : (0778) 412776 / (0778) 741569.

\section{Jenis Penelitian}

Jenis penelitian yangdigunakan adalah penelitian kualitatif yaitu metode dimana data yang diperoleh kemudian disusun, dikelompokkan, dianalisis sehinggah memperoleh gambaran yang sebenarnya, dimana penulis mengamati pengendalian intern penerimaan kas dari piutang di PT.Trans Multi Cargo.

\section{Jenis Data}

1. Data Primer

2. Data Sekunder

\section{Teknik Pengumpulan Data}

1. Studi Lapangan
a. Observasi
b. Wawancara
c. Dokumentasi

2. Studi Kepustakaan 


\section{Teknik Analisis Data}

Teknik analisis data yang digunakan adalah deskriptif. Adapun langkah-langkah yang akan dilakukan adalah dengan mendeskripsikan prosedur penagihan piutang dan sistem pengendalian intern penerimaan kas dari piutang yang diterapkan PT.Trans Multi Cargo dengan mengetahui struktur organisasi yang dijalankan, fungsi yang terkait dan dokumen yang digunakan. Analisis data dilakukan dengan cara membandingkan hasil penelitian dengan teori yang relevan berdasarkan teori Mulyadi (2016) yang terdiri dari organisasi, sistem wewenang dan prosedur pencatatan, praktik yang sehat, karyawan yang bermutu. Dan untuk menguji efektivitas sistem pengendalian intern terhadap penerimaan kas dari piutang dilakukan uji kepatuhan dengan metode StopOr-Go Sampling.

\section{HASIL PENELITIAN DAN PEMBAHA- SAN}

\section{Gambaran Umum Perusahaan}

PT. Trans Multi Cargo pertama kali didirikan di Pekanbaru pada bulan September 1998 yang berlokasi di Jalan Singkawang - Jati No.10, Pekanbaru. Dan untuk dikota Batam PT.Trans Multi Cargo didirikan pada tanggal 9 Februari 2008 oleh Bapak Ronald Raja Siregar selaku pemengan saham dimana jabatannya adalah sebagai Direktur dengan Akta Notaris Hatma Wigati Kartono, SH No.245 di Komp.Regency Park Blok IV/46, JL. Sriwijaya - Batam. Sejak izin Publikasi Kementerian Lingkungan Hidup Indonesia tahun 2005, perusahaan ini menjadi salah satu perusahaan sebagai mengumpulkan dan mengangkut semua jenis limbah dari produser perusahaan di Pulau Batam, Sumatera, Lombok (NTT) dan memberikan layanan kepada seluruh Indonesia. Perusahaan ini dijalankan yang berdasar pada komitmen penuh untuk memberikan layanan yang terbaik.

\section{Proses Terjadinya Piutang Pada PT.Trans Multi Cargo}

Piutang pada PT.Trans Multi Cargo dimulai dari permintaan jasa dari pelanggan, setelah terjadi kesepakatan mengenai harga dan rencana pelaksanaan kegiatan maka akan dibuatkan Purchase order oleh bagian customer service. Untuk kesepakatan harga biasanya bagi pelanggan baru pembayaran uang muka $50 \%$ dari total harga dan sisanya akan ditagih setelah invoice keluar, dan untuk pelanggan lama maka akan dilakukan pengecekan oleh bagian piutang berdasarkan riwayat pembayaran pelanggan atas status kredit yang pernah terjadi. Jika kedua belah pihak telah setuju untuk orderan maka petugas bagian lapangan akan melakukan pekerjaan sesuai dengan surat tugas yang telah diterbitkan oleh inspektor. Setelah pekerjaan selesai maka inspektor akan menyerahkan hasil pekerjaan lapangan kebagian adminitrasi dokumen untuk dibuat sertifikat/report. Berdasarkan nomor sertifikat/report yang dibuat inilah bagian $A / R$ dan $\mathrm{A} / \mathrm{P}$ administrasi (bagian piutang) akan membuat invoice/tagihan untuk pelanggan.

Bagian piutang akan mendistribusikan invoice kepada pelanggan apabila barang sudah sampai tujuan.

\section{Prosedur Penagihan Piutang}

Kebijakan perusahaan pada proses penagihan piutang dilakukan sesuai dengan term of payment (TOP) yang sudah ditetapkan dengan tepat waktu. Bagian piutang terlebih dahulu akan mengrimin invoice melalui e-mail kepada pelanggan sebelum piutang jatuh tempoh, lalu bagian piutang akan menghubungi pelanggan melalui telepon bahwa akan dilakukan penagihan piutang terhadap piutang yang akan jatuh 
tempoh melalui penagih perusahaan. Berikut proses penagihan piutang yang dilakukan PT. Trans Muti Cargo :

1. Bagian piutang (A/R dan $\mathrm{A} / \mathrm{P}$ Administrasi) akan menyiapkan daftar piutang yang sudah saat ditagih berserta kelengkapan dokumen lainnya seperti invoice, kwitansi, copy kontrak, faktur pajak dan laporan progress yang sudah lengkap ke bagian penagihan untuk dilakukan penagihan terhadap pelanggan.

2. Bagian penagihan akan menerima dan memeriksa daftar piutang pelanggan yang akan ditagih berserta kelengkapan dokumen lainnya yang diterima dari bagian piutang. Lalu bagian penagih perusahaan akan mengirimkan tagihan kepada pelanggan yang piutangnya sudah mendekati tanggal jatuh tempoh.

3. Bagian penagihan akan menerima surat pemberitahuan dan memeriksa kembali hasil tagihan yang diperoleh baik berupa uang tunai, bilyet giro, cek dan invoice yang tak tertagih dan akan menyerahkan hasil tagihan ke bagian finance. Lalu bagian penagihan melaporkan hasil tagihan kebagian piutang dan menyerahkan kembali invoice yang tidak berhasil ditagih disertai dengan alasannya pada hari yang sama serta melaporkannya kebagian accounting.

4. Bagian finance yang sudah menerima hasil tagihan akan melakukan pencatatan dibuku kasnya sebagai penerimaan kas dari pelunasan piutang pelanggan.

5. Bagian finance akan membuat kwitansi dan mengirimkannya kepada debitur sebagai tanda bukti pembayaran yang telah diterima.

6. Bagian finance akan menyetor hasil tagihan ke rekening perusahaan setelah dilakukan endorsement oleh pejabat yang berwenang. Dan akan membuat bukti setor bank yang akan diserahkan kebagian accounting untuk dilakukan penjurnalan dan melaporkan kebagian piutang untuk dilakukan rekapitulasi terhadap buku piutang.

\section{Prosedur Penerimaan Kas Dari Piutang}

1. Bagian piutangakan menyiapkan daftar piutang yang mendekatitanggal jatuh jatuh tempo dengan kelengkapan dokumen lainnya untuk dilakukan penagihan, lembar pertama akan diserahkan kebagian penagihan, lembar kedua diserahkan kebagian finance, dan lembar ketiga diarsip.

2. Bagian penagihan akan menyiapkan surat tagihan untuk pelanggan sesuai dengan daftar piutang dan invoice yang sudah ada.

3. Bagian penagih akan menerima uang tunai/cek/bilyet giro dan surat pemberitahuan dari pelanggan.

4. Bagianpenagihanakan menyerahkan uang tunai/cek/bilyet giro, lembar pertama daftar piutang ditagih dan surat pemberitahuan akan akan diarsip dan hasil tagihan diserahkan ke bagian finance.

5. Bagian finance akan membandingkan daftar piutang yang ditagih dengan uang / hasil tagihan yang diterima dari penagih perusahaan dan akan membuat kwitansi rangkap 2 . Lembar pertama diserahkan kepada pelanggan dan lembar kedua diarsip, lalu hasil tagihan akan disetorkan ke bank dan membuat laporan bukti setor bank yang akan diserahkan kebagian accounting.

6. Bagian accounting akan mencocokkan bukti setor bank dari bagian finance dengan uang masuk yang ada direkening bank perusahaan dan 
daftar piutang yang ditagih, lalu bagian accounting akan membuat bukti kas masuk rangkap 2 lembar pertama digunakan sebagai dasar penjurnalan dan akan disimpan lalu lembar kedua diserahkan kebagian piutang untuk proses pencatatan ke kartu piutang.

\section{Sistem Pengendalian Intern Penerimaan Kas Dari Piutang}

1. Fungsi Yang Terkait

- Fungsi administrasi

- Fungsi piutang

- Fungsi penagihan

- Fungsi finance

- Fungsi accounting

2. Dokumen Yang Digunakan

- Invoice

- Kwitansi

- Purchase order

- Bukti bank masuk

- Bukti setor bank

- Bilyet giro

3. Catatan akuntansi yang digunakan

- Jurnal penerimaan kas

- Kartu piutang

- Buku besar pembantu piutang

4. Praktik yang sehat

- Setiap transaksi bernomor urut cetak untuk dapat dipertanggungjawabkan

- Setiap terjadi transaksi penerimaan kas disetor ke rekening bank yang dimiliki PT.Trans Multi Cargo

- Secara periodik dilakukan pencocokan antara fisik kas yang ada pada bagian finance dengan catatan yang ada pada bagian accounting.

5. Karyawan yang mutunya sesuai Sistem pengendalian intern yang baik tidak lepas dari sumber daya manusia yang melaksanakannya. PT. Trans Multi Cargo menerapkan beberapa langkah dalam perekrutan karyawan seperti perekrutan dan penempatan karyawan dilaksanakan dengan mengadakan seleksi yang selektif dengan menetapkan beberapa job requirements sesuai dengan job position yang dibutuhkan, menentukan batas mininal pendidikan sesuai dengan job position yang dibutuhkan sebagai kriteria seleksi, mengadakan pelatihan bagi karyawan, dan adanya kesempatan bagi karyawan untuk mengembangkan pendidikannya.

\section{Analisis Sistem Pengendalian Intern Pen- erimaan Kas Dari Piutang}

Data - data yang diolah berkaitan dengan kegiatan penjualan jasa secara kredit melalui wawancara dan pengamatan langsung yang dilakukan bertujuan untuk menganalisis efektivitas pengendalian intern terhadap penerimaan kas dari piutang. Tahap ini dilakukan dengan cara membandingkan pengendalian intern perusahaan dengan teori Mulyadi (2016). Berdasarkan hasil analisis tersebut dapat diidentifikasi aspek - aspek sistem pengendalian intern penerimaan kas dari piutang pada perusahaan tersebut sebagai berikut :

1. Pemisahan Tanggung Jawab

FungsionalSecara Tegas

(StrukturOrganisasi)struktur organisasi perusahaan telah menggambarkan pemisahan fungsi dan tanggungjawab sesuai dengan tugasnya masing-masing diantaranya :

a. Fungsi piutang yang telah dilakukan oleh A/R dan A/P Administrasi.

b. Penagihan perusahaan yang telah dilakukan oleh bagian Penagih.

c. Penerimaan hasil penagihan yang telah dilakukan oleh bagian finance.

d. Pencatatan dan pembukuandilakukan oleh bagian $a c$ counting. 
2. Aspek Wewenang Dan Prosedur Pencatatan

Sistem wewenang dan prosedur pencatatan konsumen diminta untuk melakukan pembayaran dalam bentuk cek atas nama atau dengan bilyet giro (pemindahbukuan). Pembayaran piutang yang dilakukan dalam bentuk uang tunai akan dilakukan oleh bagian penagih perusahaan. Bagian penagihan telah menjalalankan tugasnya dengan melakukan penagihan hanya atas dasar daftar piutang yang harus ditagih yang dibuat oleh bagian piutang. Pengkreditan rekening pembantu piutang oleh bagian piutang didasarkan pada bukti bank masuk yang dibuat oleh bagian accounting.

3. Aspek Praktik Yang Sehat

Ada penggunaan formulir bernomor urut agar tidak dapat dipalsukan dan dapat dipertanggungjawabkan, pelaksanaan transaksi tidak hanya dilakukan oleh satu orang saja dan secara periodik dilakukan pencocokan antara fisik kas dengan catatan akuntansi. Namun pada PT. Trans Multi Cargi belum diterapkan pemeriksaan mendadak dan tim organisasi yang bertugas dalam melakukan pegawasan dan mengecek efektifitas pengendalian internal lainnya seperti pegawasan dalammelakukan penagihan piutang terhadap pelanggan.

4. Aspek Karyawan Yang Mutunya Sama Dengan TanggungJawabnya

Seleksi calon pegawai PT.Trans Multi Cargo dilaksanakan secara selektif. Jenis pendidikan calon pegawai juga sangat berpengaruh pada jabatan yang akan didudukinya, calon pegawai harus memiliki keahlian dibidangnya, jujur dan disiplin juga menjadi kriteria perekrutan karyawan. Dengan dilaksanakannya seleksi untuk memilih karyawan yang berkualitas dapat menunjang pencapaian tujuan perusahaan, karena operasional perusahaan ditangani oleh karyawan yang cakap dan bertanggungjawab. Mengadakan pelatihan terhadap calon karyawan yang sesuai dengan bidangnya hal ini dapat memberi efek yang baik bagi perusahaan. Hal tersebut dapat meningkatkan skill karyawan sehingga terjaga kualitas kerja karyawan yang membawa manfaat bagi perusahaan terutama terkait efesiensi dan efektivitas operasional perusahaan. Namun walaupun diperusahaan ini tidak diadakan rotasi jabatan tetap dikatakan baik karena para karyawan telah mampu menyelesaikan tugas sesuai dengan fungsi dan tanggungjawabnya masing-masing.

\section{Efektivitas Sistem Pengendalian Intern- Penerimaan Kas Dari Piutang}

Untuk menilai keefektifan sistem pengendalian intern dalam penerimaan kas dari piutang, dilakukan pengujian kepatuhan dengan menggunakan attribute sampling dengan model Stop-Or-Go Sampling. Populasi yang digunakan adalah semua bukti kas masuk beserta dokumen pendukungnya berupa invoice, surat pemberitahuan, dan bukti setor.

Adapun langkah yang dilakukan dalam pengujian kepatuhan terhadap sistem pengendalian intern penerimaan kas dari piutang yaitu :

\section{a. Menentukan attribute}

Yang dimaksud attribute disini adalah sesuatu yang menjadi unsur dalam setiap bukti transaksi penerimaan kas. Attribute yang diperiksa adalah :

1. Kelengkapan dokumen pendukung seperti kwitansi, invoice, surat pemberitahuan dan bukti setor.

2. Tandatangan dan otorisasi disetiap bukti kas masuk

3. Kecocokan nomor urut cetak disetiap bukti kas masuk 
4. Kecocokan informasi mengenai jumlah, jenis jasa dan harga dengan dokumen pendukung

b. Menentukan populasi yang akan dijadikan sampel

Populasi dalam penelitian ini yang akan diambil sampelnya adalah bukti kas masuk beserta dokumen pendukungnya. Bukti kas masuk merupakan sumber yang dipakai perusahaan sebagai catatan penerimaan kas dan pelunasan dari pelanggan.

c. Menentukan besarnya sampel

Penentuan tingkat keandalan confidence level disingkat R\% yaitu sebesar $95 \%$ dan DUPL sebesar $5 \%$.

2. Dalam penelitian ini ditetapkan tingkat keandalan sistem pengendalian intern penerimaan kas dari piutang yakni $95 \%$ dan DUPL 5\% dengan menggunakan tabel penentuan jumlah sampel minimum Stop-Or-Go Sampling dapat diketahui bahwa dengan tingkat keandalan 95\% dan DUPL 5\% jumlah sampel minimum 60 sampel.

d. Memilih anggota sampel

Selanjutnya memilih anggota sampel sebanyak 60 yaitu berdasarkan bukti kas masuk beserta dokumen pendukung seperti invoice, kwitansi, surat pemberitahuan, dan bukti setor.

e. Pemeriksaan terhadap sampel Pada tahap ini jika saat pengecekan ditemukan ada penyimpangan terhadap attribute, peneliti mencatat berapa banyak penyimpangan yang ditemui namun jika tidak ada maka dibuat tanda ceklis $(\sqrt{ })$.

Keterangan :

Attribute 1 : setiap penerimaan kas dilampirin dokumen pendukung

Attribute 2 : otorisasi kepala bagian dalam bukti kas masuk

Attribute 3 : ada kecocokkan nomor urut tercetak dengan yang dilampirkan
Attribute 4 :pemeriksaan terhadap invoice, kwitansi, surat pemberitahuan dan bukti setor

Berdasarkan hasil penelitian tersebutternyata tidak ditemukan penyimpangan artinya jumlah kesalahan sama dengan nol.

\section{f. Analisis hasil pemeriksaan sampel}

Berdasarkan hasil pemeriksaan jumlah kesalahan adalah nol, kemudian ditentukan confidence level factor pada $\mathrm{R} \%=95 \%$ dan confidence level adalah 3.

Tabel 4.7

\section{Stop Or Go Sampel Size dan Upper Pre- cision Limit Population Accurance Rate On Sampel Results}

\begin{tabular}{|c|c|c|c|}
\hline \multirow{2}{*}{$\begin{array}{c}\text { Number } \\
\text { of } \\
\text { Occurance }\end{array}$} & \multicolumn{3}{|c|}{ Confidance Level } \\
\cline { 2 - 4 } & $\mathbf{9 0} \%$ & $\mathbf{9 5 \%}$ & $\mathbf{9 7 , 5} \%$ \\
\hline 0 & 2,4 & 3,0 & 3,7 \\
\hline 1 & 3,9 & 4,8 & 5,6 \\
\hline 2 & 5,4 & 6,3 & 7,3 \\
\hline
\end{tabular}

Selanjutnya menentukan AUPL dengan rumus berikut :

$$
\text { AUPL }=\frac{\begin{array}{c}
\text { Confidence level } \\
\text { factor at desired } \\
\text { reliability level } \\
\text { for occurrances } \\
\text { observed }
\end{array}}{\text { Sampel Size }}
$$

Dari rumus diatas dicari dengan memasukan julah sampel dengan tingkat kesalahan yang telah diketahui sebagai berikut :

AUPL $=3 / 60$

$$
=0,055 \%
$$


Maka analisis hasil pemeriksaan sampel dapat dijelaskan sebagai berikut :

Tabel 4.8

Analisis Hasil Pemeriksaan Dokumen Sistem Penerimaan Kas Dari Piutang PT.Trans Multi Cargo

\begin{tabular}{|c|c|c|c|c|c|}
\hline $\begin{array}{c}\text { No } \\
\text { Attri } \\
\text { bute }\end{array}$ & $\begin{array}{c}\text { Jmlh } \\
\text { Sam } \\
\text { pel }\end{array}$ & $\begin{array}{c}\text { Jmlh } \\
\text { Kesa } \\
\text { lahan }\end{array}$ & $\begin{array}{c}\text { DU } \\
\text { PL }\end{array}$ & $\begin{array}{c}\text { AU } \\
\text { PL }\end{array}$ & Sifat \\
\hline 1 & 60 & 0 & $5 \%$ & $5 \%$ & Efektif \\
\hline 2 & 60 & 0 & $5 \%$ & $5 \%$ & Efektif \\
\hline 3 & 60 & 0 & $5 \%$ & $5 \%$ & Efektif \\
\hline 4 & 60 & 0 & $5 \%$ & $5 \%$ & Efektif \\
\hline
\end{tabular}

Diketahui bahwa AUPL $=5 \%$ dan DUPL $=5 \%$, sehingga AUPL $=$ DUPL dengan demikian dapat disimpulkan penerimaan kas dari piutang di PT.Trans Multi Cargo sudah efektif, karena AUPL tidak melebihi DUPL.

\section{KESIMPULAN DAN SARAN Kesimpulan}

Berdasarkan hasil penelitian dan pembahasan yang telah dilakukan penulis mengambil kesimpulan bahwa sistem pegendalian intern penerimaan kas dari piutang di PT. Trans Multi Cargo sudah berjalan dengan baik. Hal ini tercermin dari sudah terpenuhinya unsur-unsur sistem pengendalian intern seperti struktur organisasi sesuai dengan pemisahan fungsi dan tugasnya, pencatatan sudah dilakukan dengan baik, penagihan sudah dilakukan sesuai umur piutang walaupun tidak ada perputaran jabatan namun setiap karyawan telah mampu melaksanakan tugasnya dan dari hasil pengujian kepatuhan terhadap sistem pengendalian intern penerimaan kas dari piutang di PT.Trans Multi Cargo tidak ditemukan adanya penyimpangan . pada tingkat kesalahan sama dengan 0 , confi- dence level factor pada $\mathrm{R} \%=95 \%$ adalah 3 , dengan demikian diperoleh AUPL = DUPL sebesar 5\%, sehingga dapatditarik kesimpulan bahwa sistem pengendalian intern penerimaan kas dari piutang sudah efektif.

\section{Saran}

Dari kesimpulan yang telah di uraikan di atas, maka penulis mencoba memberikan saran yang mungkin dapat berguna dalam pengambilan keputusan oleh pimpina perusahaan untuk menerapkan sistem pengendalian intern dimasa yang akan datang, adapun saran diberikan penulis adalah:

1. Sebaiknya membuat daftar surat pemberitahuanmengenai rekapitulasi kas sehingga mempermudah mengetahui jumlah rekapitulasi penerimaan kas dari piutang

2. Sebaiknyadibentukfungsipemeriksaan intern dan melakukan pemeriksaan secara mendadak yang dilaksankan tanpa pemberitahuan kepada pihak terkait

3. Dilakukannya perputaran jabatan setiap periode agar dapat terciptanya efektivitas terhadap tugas dan wewenang sehingga dapat memimalisirkan adanya penyelewengan kas.

4. Dibuat kebijakan khusus mengenaibatasan kredit pelanggan, sanski bagi keterlambatan pembayaran.

\section{DAFTAR PUSTAKA}

Eni Pirnawati, 2013. Sistem Akuntansi Penerimaan Kas Dari Piutang Pada Koperasi Erba Usaha (KSU) Makmur Abadi Kecamatan Kayen Kabupaten Pati, Universitas Negeri Semarang. 
Heri Sukendar, 2010. Sistem Informasi

Akuntansi Penjualan, Piutang dan Penerimaan

Kas Pada PT.Nakami

Kinema Cemerlang. Universitas Bina Nusantara, Binus Business Review

Vol. 1 No.1 Mei 2010:1-14, Jakarta Barat.

Hery, 2013. Akuntansi Keuangan Menengah, CAPS (Center of Academic Publishing Service), Yogyakarta.

Krismiaji, 2015. Sistem Informasi Akuntansi, Sekolah Tinggi Ilmu Manajeme YKPN, Yogyakarta.

Mulyadi, 2016. Sistem Akuntansi; Edisi IV, Salemba Empat, Jakarta.

Nena Seoulinda; Aries Wicaksono, 2012.

Evaluasi Pengendalian Internal Dan Sistem Akuntansi Atas Penerimaan Kas Dan Piutang Premi Asuransi Pada Pt H. Jakarta. BINUS BUSINESS REVIEW

Vol. 3No. 2 November 2012: 983-992.

Soemarso S.R. 2010. Akuntansi Suat Pengantar; Edisi Kedua, Buku 1, Salemba Empat, Jakarta. 